\title{
Transgenerational Genomics: The profession should enhance its role as advocate for the health of the next generation
}

Peter Braude ${ }^{1}$ and Edward Morris ${ }^{2}$

${ }^{1}$ King's College London

${ }^{2}$ Norfolk and Norwich University Hospitals NHS Foundation Trust

November 2, 2020

\section{Hosted file}

BJOG Transgenerational Genomics v12.3.pdf available at https://authorea.com/users/372238/ articles/490347-transgenerational-genomics-the-profession-should-enhance-its-role-asadvocate-for-the-health-of-the-next-generation 